\title{
Ivermectin: pharmacology and therapeutic applications
}

\author{
Sunita B. Chhaiya ${ }^{a, *}$, Dimple S. Mehta ${ }^{a}$, Bhaven C. Kataria ${ }^{b}$
}

${ }^{a}$ Department of Pharmacology, C.U. Shah Medical College, Surendranagar 363001, India,

${ }^{\mathrm{b}}$ Department of Pharmacology, GCS

Medical College, Hospital and Research

Centre, Ahmedabad 380025, India

Received: 25 September 2012

Accepted: 28 October 2012

*Correspondence to:

Dr. Sunita B. Chhaiya,

Email: s_chhaiya@rediffmail.com

\begin{abstract}
Ivermectin is an antiparasitic drug with a broad spectrum of activity, high efficacy as well as a wide margin of safety. It belongs to the family of avermectins. It binds to glutamate-gated chloride iron channels, which are present in invertebrate nerve and muscle cells, and causes the paralysis and death of the parasite. Ivermectin is approved by the US Food and Drug Administration, and used worldwide to treat patients with onchocerciasis and strongyloidiasis. It is also used against a wide range of endoparasites (nematodes) and ectoparasites (insects, acarine) of animals and humans.
\end{abstract}

Keywords: Antiparasitic, Onchocerciasis, Strongyloidiasis, Scabies, Trichuris trichiura, Filariasis

\section{INTRODUCTION}

Ivermectin (MK-0933, 22, 23-dihydroderivative of amvermectin B1) is a synthetic derivative of a broadspectrum antiparasitic class of macro cyclic lactones known as avermectins. Avermectin B was first isolated by fermentation of a soil microorganism, the actinomycete Streptomyces avermitilis. Ivermectin has a structure similar to that of macrolide antibiotics, but without antibacterial activity (Figure 1). ${ }^{1}$

\section{MECHANISM OF ACTION}

Ivermectin acts by binding selectively to specific neurotransmitter receptors that function in the peripheral motor synapses of parasites. It has an endectocidal effect (simultaneously against India and ectoparasites) causing paralysis of nematodes, arthropods and insects by suppressing the conduction of nervous impulses in the interneuronic (intermediary neurons) synapses of nematodes and the nerve-muscle synapses of the arthropods and insects. ${ }^{3}$

Ivermectin blocks chemical transmission across the nerve synapses that use glutamate-gated anion channels or $\gamma$ aminobutyric acid- gated chloride channels. Stimulation of $\gamma$-aminobutyric acid (GABA) release from presynaptic nerve endings and enhancement of the binding to the postsynaptic receptors accomplishes this. ${ }^{4,5}$ Ivermectin does not affect synapses gated by other transmitter substances, such as acetylcholine, nor epinephrine, and serotonin. ${ }^{6}$ This leads to an increase in the permeability of the cell membrane to chloride ions with the hyper polarization of the cell, resulting in paralysis and death of the parasite (Figure 2). ${ }^{7}$

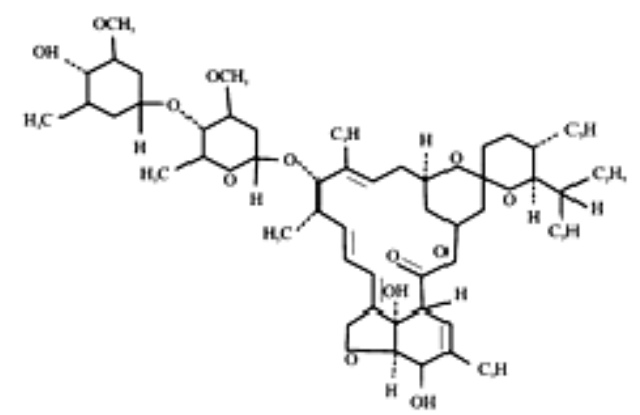

Figure 1: Structure of ivermectin ${ }^{2}$

In humans GABA and glutamate do not affect peripheral motor function. Thus, ivermectin selectively paralyzes invertebrates. Ivermectin is well tolerated by mammals because glutamate-gated anion channels or GABA-gated chloride channels are localized only in the central nervous system; the drug cannot penetrate through the hematoencephalic barrier. ${ }^{2}$ 


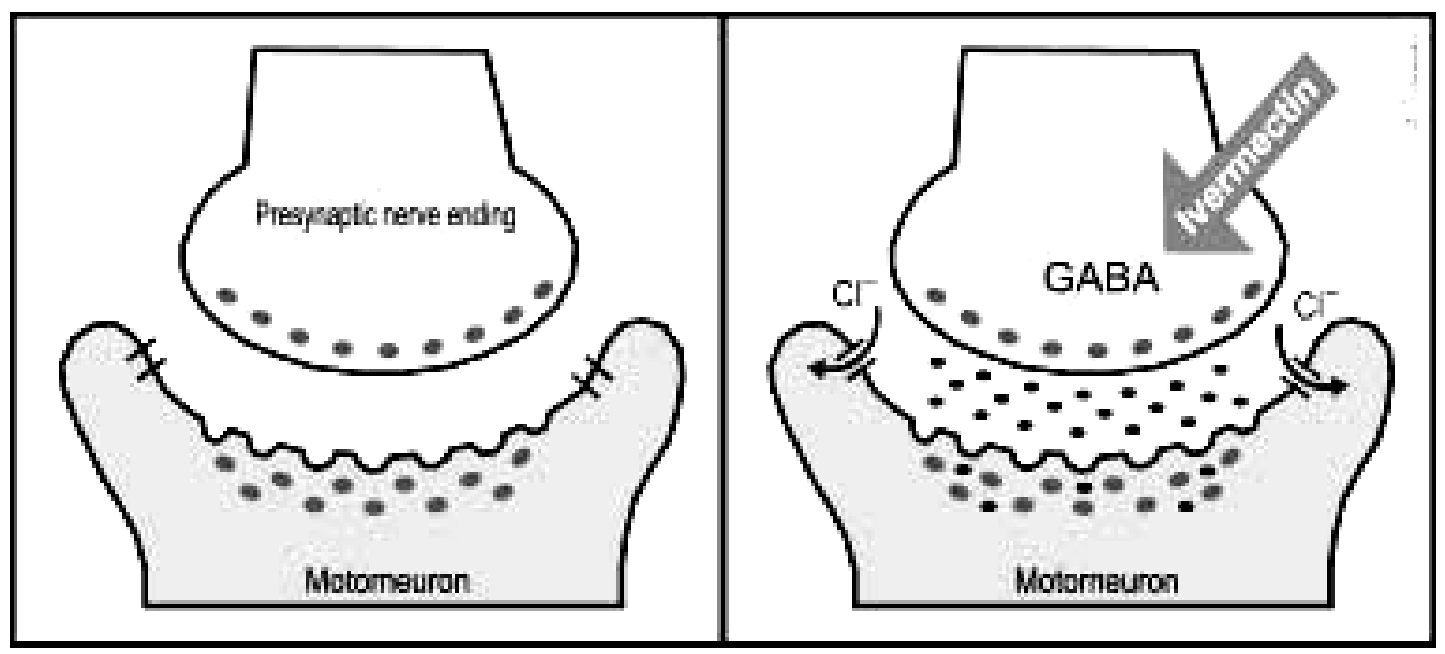

Figure 2: Ivermectin action of $\gamma$-aminobutyric acid (GABA) -gated chloride channels in the interneuronic synapses of a parasite (i.e. Increased release of GABA at the presynaptic nerve ending; opening of the chloride ion channels; increased binding GABA at the motor neuron). ${ }^{2}$

\section{PHARMACOKINETIC}

It is absorbed rapidly and given orally on an empty stomach, metabolized in the liver and excreted in the feces $(98 \%)$ and urine $(1 \%)$. Minimal concentration of this drug has been observed in human milk. Concentration of ivermectin in blood peaks at $30-46 \mathrm{ng}$ $/ \mathrm{mL}$ around $4 \mathrm{~h}$ post doses, and slowly decreases thereafter. $^{8,9}$ Peak plasma concentration of metabolites remains longer than that of the parent drug, suggesting enterohepatic recycling. Ivermectin was present in fat, skin, subcutaneous fascia and nodules. ${ }^{10}$ Ivermectin reaches peak plasma levels $5 \mathrm{~h}$ after oral administration and has a half-life of $36 \mathrm{~h} .{ }^{11}$ The peak concentration of the drug in squames, sebum and sweat on the forehead and the antithenar was $8 \mathrm{~h}$ after a single $12-\mathrm{mg}$ oral dose and declined after $24 \mathrm{~h}^{12}$

\section{SAFETY AND ADVERSE REACTIONS}

Transient and mild adverse reactions have been reported in $24 \%$ of filarial disease patients, with signs and symptoms including anorexia, asthenia, headache, arthralgia, myalgia, fever, and eosinophilia. Mazzotti reactions and sudden death from the release of degradation products of microfilaria were observed in patients with filarial diseases. ${ }^{13}$ Macular and papular rashes and pruritus (33\%) between 2 and 4 days after oral ivermectin in patients with scabies has been noted. (This adverse reaction is the result of the release of toxic products from dying or dead mites.) Hematomas and an increase in prothrombin time in a few patients have been observed. Occasionally, nausea and a decrease in blood pressure, as well as flat $\mathrm{T}$ waves or prolonged PR times on ECG, have been described. ${ }^{14}$
On the basis of a statistical study it was suggested that the death in 15 out of 47 elderly patients may have been associated with a single oral dose of ivermectin $(0.15-0.2 \mathrm{mg} / \mathrm{kg})$ for treatment of scabies. ${ }^{15}$ According to some observations the mortality rate 6 months after treatment did not differ significantly from that seen 30 months before treatment. ${ }^{16,17}$

\section{DRUG INTERACTIONS}

To interrupt the transmission of onchocerciasis in humans, the combination of ivermectin and doxycycline is highly effective as, in infested patients, the ingestion of the anthelmintic $(200 \mu \mathrm{g} / \mathrm{kg}$, single dose) and the antibacterial $(100 \mathrm{mg} / \mathrm{kg}$, daily for 6 weeks), kept the microfiladermia levels low more time than did ivermectin alone. Doxycycline enhanced ivermectin-induced suppression of microfiladermia, as it sterilizes adult female worms for a few months by depletion of symbiotic endobacteria of filariae, Wolbachia spp. essential for their survival and reproduction). ${ }^{18}$

Also in onchocerciasis patients, the antiparasitic efficacy was similar when administering a single ivermectin dose $(150 \mu \mathrm{g} / \mathrm{kg}$, on day 1$)$ followed by amorcazine ( 3 $\mathrm{mg} / \mathrm{kg}$ twice daily, on days 8,9 and 10) than when administering ivermectin alone. ${ }^{19}$ Similarly, the combination of ivermectin $(200 \mu \mathrm{g} / \mathrm{kg})$ and levamisole $(2.5 \mathrm{mg} / \mathrm{kg}$ ) was neither macrofilaricidal nor more effective against the microfilariae and the adult worms than ivermectin alone, although levamisole increased ivermectin plasma bioavailability in these patients. ${ }^{20}$

The efficacy of drugs available for the treatment of infection with Trichuris trichiura is low in humans. Single dose treatment with albendazole $(400 \mathrm{mg})$ and 
ivermectin $(200 \mu \mathrm{g} / \mathrm{kg})$ appears to be highly effective against trichuriasis, being higher than when administering albendazole alone or with diethylcarbamazine (6 $\mathrm{mg} / \mathrm{kg})^{21}$ Thus, ivermectin interactions with another concurrently administered drug can occur. This issue became important, as combination chemotherapy is being used with increasing frequency as resistance to antiparasitic agents is becoming more widespread. ${ }^{10}$

A man that had been on long term oral anticoagulant therapy with acenocoumarol showed a persistent, excessive hypocoagulability while using insecticides (ivermectin and metidation) without protection to treat trees. These types of interactions can exist and could cause hemorrhagic complications. ${ }^{10}$

The influence of alcohol in ivermectin kinetic behavior is scarce; co-ingestion of alcoholic drinks however is not recommended, because of ivermectin association with GABA receptors and the effect of alcohol in the central nervous system. In healthy volunteers administered ivermectin orally $(150 \mu \mathrm{g} / \mathrm{kg})$, plasma levels were significantly higher when co administered with $750 \mathrm{ml}$ of beer than with $750 \mathrm{ml}$ of water. ${ }^{22}$ Ivermectin $(150 \mu \mathrm{g} / \mathrm{kg})$ was administered to 16 individuals with water or orange juice $(750 \mathrm{ml})$. Orange juice decreased AUC (15.7 ng.d.ml -1) and Cmax (20.7 ng.ml-1), possibly because fruit juices and constituents are potent inhibitors of certain drug transporters. ${ }^{23}$

\section{THERAPEUTIC USES IN DERMATOLOGY}

Ivermectin is used in dermatology against some parasitic infestations in humans with cutaneous tropism. The drug is of great interest in the treatment of patients with different forms of scabies, human body lice, head lice, demodecicosis, cutaneous larva migrans, cutaneous larva currens, myiasis, and filariasis. ${ }^{2}$

\section{ONCHOCERCIASIS (AFRICAN RIVER BLINDNESS)}

Onchocerca volvolus infestation is characterized by disseminated prurigo, lichenification, and subcutaneous nodules (onchocercomas) on the trunk and extremities. ${ }^{24}$ Infestation of the eye leads to blindness. Ivermectin was introduced against Onchocerca volvolus, ${ }^{25}$ and has been used extensively in humans to control endemic onchocerciasis. ${ }^{26}$ Ivermectin causes a dramatic decrease of the microfilarial load in the skin of patients with onchocerciasis and thus leads to a clinical improvement of the symptoms. ${ }^{27}$ When used as a single annual or semiannual dose, ivermectin has no effect on the adult female filaria, whose life may last 14 years or longer. Thus to maintain the beneficial effect of the treatment, ivermectin must be given repeatedly throughout the lifespan of the parasite. $^{28}$ Two therapeutic options have shown some encouraging results. First, ivermectin combined with long-term treatment with doxycycline may cause the sterilization of the adult female worm, perhaps permanently. ${ }^{18}$ Secondly, increasing the frequency of ivermectin distribution from annually to every 3 months decreases the fecundity of the adult female parasite twoto-threefold and this effect is long-lasting. ${ }^{29}$

\section{FILARIASIS}

Filariasis is an infestation by filarial worms (Filaria bancrofti, Wuchereria malayi) whose vectors are mosquitoes (Culex, Anopheles, Aedes and Mansonia). Clinical manifestations commence after a long incubation period and include acute lymphangitis of the legs, lymphadenitis, and orchitis, and finally lead to elephantiasis. Patients with filariasis have been treated with oral ivermectin; microfilaria rapidly disappears but the efficacy is temporary, necessitating repeated courses. $^{30,31}$

\section{LYMPHATIC FILARIASIS}

Ivermectin given as a single annual dose of $200 \mathrm{mcg} / \mathrm{kg}$ body weight or higher, with or without combination with diethylcarbamazine have great potential as a therapeutic strategy to control bancroftian filariasis. However, there are controversies regarding co-administration of ivermectin with diethylcarbamazine or albendazole. The combination of ivermectin and diethylcarbamazine was significantly more efficient than diethylcarbamazine alone in a large study performed in Papua New Guinea. ${ }^{31}$ It has been shown in Ghana that the difference in efficacy between the combination of ivermectin and albendazole and ivermectin alone appeared minimal after 12 months, whereas albendazole alone demonstrated significantly decreased efficacy. ${ }^{32}$

\section{CUTANEOUS LARVA MIGRANS}

Cutaneous larva migrans is caused by cutaneous penetration of larvae of animal hookworms (usually Ancylostoma braziliense). Patients with this disease have been successfully treated with a single 12-mg oral dose $(200 \mathrm{mcg} / \mathrm{kg})$ of ivermectin. ${ }^{33,34,35}$ Pruritus resolved completely in every case, while the progression of the larva tracts was stopped within $48 \mathrm{~h}^{33}$

\section{CUTANEOUS LARVA CURRENS}

Larva currens is a cutaneous manifestation of strongyloidiasis. ${ }^{36}$ Three patients with clinical manifestations of larva currens and a positive stool test for Strongyloides stercoralis larvae were treated with a 12-mg oral dose of ivermectin. Three months later two patients had been cured. The third patient who had not been affected by this treatment was given a further 24-mg dose of ivermectin for two consecutive days. Three months later she was asymptomatic. ${ }^{37}$

\section{DEMODECIDOSIS}


Demodex folliculorum is a normal inhabitant of human skin. In immunosuppressed patients it causes facial or disseminated demodecidosis that can be a therapeutic challenge. Two children with acute leukemia and disseminated demodecidosis were treated successfully with a single oral dose of $250 \mathrm{mcg} / \mathrm{kg}$ of ivermectin. Relapses after 6 months were also treated with a new dose. Treatment of papulopustular rosacea-like facial demodicicosis with oral ivermectin and topical permethrin $5 \%$ was also successful. ${ }^{2}$

\section{MYIASIS}

Cutaneous myiasis is an infestation of humans by fly larvae. Four cases of traumatic myiasis caused by Cochliomyia hominivorax were topically treated with $1 \%$ ivermectin in propylene glycol $\left(400 \mathrm{mcg} / \mathrm{kg}\right.$ ) for $2 \mathrm{~h}^{38}$ Within 15 min the pain decreased and after $1 \mathrm{~h}$ most of the larvae died. After $24 \mathrm{~h}$ no viable larvae remained. Twenty-nine patients with furuncular myiasis from Dermatobia hominis were effectively treated with topical ivermectin (10\% in propylene glycol) for $2 \mathrm{~h}$. After local anesthesia the skin lesions were incised and the parasite removed by digital compression. ${ }^{39}$ A single oral dose of ivermectin $(200 \mathrm{mcg} / \mathrm{kg})$ in one patient with cutaneous myiasis resulting from $H$. lineatum was also effective, and led to spontaneous migration of the maggots. ${ }^{2}$

\section{LOIASIS}

The vector of loa-loa is the horsefly. Chrysobs induces cutaneous manifestations such as a transient prurigo nodularis- like swelling (Calabar swelling) on the upper extremities. Ivermectin is highly effective for the treatment of loiasis. ${ }^{40}$

The treatment of loiasis with ivermectin may produce severe adverse reactions, as diethylcarbamazine, but they are less frequent and is rarely life threatening. Ivermectin may also induce serious neurologic reactions in patients with high microfilaremia. ${ }^{41}$

\section{GNATHOSTOMIASIS}

It has been suggested that ivermectin should also be an effective treatment of gnathostomiasis. ${ }^{42,43}$ In one study, a single dose of $0.2 \mathrm{mg} / \mathrm{kg}$ of ivermectin gave a $95 \%$ cure rate in 21 Thai patients. ${ }^{43}$ However, these reports lack any rate of follow up (no more than six months), and in endemic countries it may be difficult to distinguish relapses from reinfections. A small series (but of imported cases with prolonged period of follow up without possibility of reinfections) suggests that treatment with ivermectin is not as efficient in tourists returning from Southeast Asian countries as it is in Thai people. $^{44}$

\section{PEDICULOSIS}

Ivermectin has systemic activity against human body lice, ${ }^{45}$ Head lice, ${ }^{46-48}$ and phtirus pubis. ${ }^{49}$ Two 200-mcg/ $\mathrm{kg}$ oral doses of ivermectin given a week apart has been shown to be effective in eradication of head lice. ${ }^{46-48}$ and phthiriasis palpebrarum. ${ }^{49}$ All adult lice were eradicated within 2 days, while the nits remained attached to the eyelashes but then disappeared. ${ }^{49}$ It has also been administered orally for pediculosis capitis in children older than 1 year. ${ }^{48}$ A few studies have reported the efficacy of oral or topical formulations in the treatment of pediculosis. Dunne et al., found that a single oral dose of $100-200 \mathrm{mcg} / \mathrm{kg}$ ivermectin had a significant effect in reducing head lice infestation when compared with controls. ${ }^{50}$ Glaziou et al. treated 26 patients with a single $200 \mathrm{mcg} / \mathrm{kg}$ oral dose of ivermectin. At day 14 after treatment, 20 responded to the treatment $(77 \%)$, and 6 patients $(23 \%)$ presented with a complete disappearance of eggs and all clinical symptoms. At day 28, some healed patients had signs of reinfestation. Therefore, the authors suggested giving a second dose at day $10 .^{46}$ Topical ivermectin has also been used with success. Youssef et al. reported that a single application of $0.8 \%$ ivermectin lotion was efficient to treat head lice in all 25 patients treated with clearance of parasites within 48 hours after application. ${ }^{51}$

\section{SCABIES}

\section{Common scabies}

Various comparative trials have been reported for the use of oral ivermectin in the treatment of ordinary scabies. Macotela-Ruiz et al. described a double blind trial which compared ivermectin $200 \mathrm{mcg} / \mathrm{kg}$, single dose versus placebo. Of the 55 patients included, 26 of 29 (79\%) were considered cured at the first visit at day 7 in the ivermectin group versus 4 over $26(16 \%)$ in the placebo group. ${ }^{52}$ Glaziou et al. described an investigator-blinded trial involving 44 subjects, which compared a single oral dose of ivermectin $200 \mathrm{mcg} / \mathrm{kg}$ with a topical treatment, benzyl benzoate $10 \%$. At day 30, 16 of $22(70 \%)$ in the ivermectin group versus 10 of $21(48 \%)$ were cured, but the difference was not significant. ${ }^{53}$ Chouela et al. compared lindane $1 \%$ solution versus $150-200 \mathrm{mcg} / \mathrm{kg}$ ivermectin in a randomized double blind study. Fiftythree patients were included, 43 completed the study. At day 15,14 patients $(74 \%)$ treated with ivermectin were healed versus $13(54 \%)$ in the lindane group. At day 29, after a repeated treatment for patients not cured, 18 patients $(95 \%)$ were healed in the ivermectin group versus $23(96 \%)$ in the lindane group. Both treatments were considered of equivalence efficacy at day $29 .^{54}$ Ivermectin had better results than lindane lotion $1 \% .^{55}$ Usha et al. reported an open randomized study comparing oral ivermectin $200 \mathrm{mcg} / \mathrm{kg}$ with $5 \%$ permethrin cream. By the first and second week respectively, 20 (50\%) and $28(70 \%)$ in the ivermectin group were cured versus 35 $(84.5 \%)$ and $44(97.8 \%)$ in the permethrin group. After a second dose, by the fourth week $38(95 \%)$ of the patients in the ivermectin group were cured. ${ }^{56} \mathrm{~A}$ trial compared oral ivermectin $200 \mathrm{mcg} / \mathrm{kg}$ single dose with topical 
benzyl benzoate $10 \%$. One hundred ten children aged 6 months to 14 years were treated, and there was no difference between the two treatments for efficacy at 3 weeks respectively and no serious side effects, but benzyl benzoate produced more skin irritation. ${ }^{57}$ Only one report fails to show any efficacy of the drug. ${ }^{50}$

Sule et al, compared benzyl benzoate $25 \%$ with oral ivermectin $(200 \mathrm{mcg} / \mathrm{kg})$. At the end of 2 weeks 77 of $98(79 \%)$ subjects in ivermectin group were cured and 60 of $102(59 \%)$ subjects were cured in benzyl benzoate group. The overall cure rate after 4 weeks was $95 \%$ in the ivermectin group and $86 \%$ in the benzyl benzoate group. ${ }^{58}$ Bachewar et al. described a randomized comparative clinical trial involving 103 patients, which compared a single oral dose of ivermectin $200 \mathrm{mcg} / \mathrm{kg}$ with topical benzyl benzoate $25 \%$ lotion and permethrin $5 \%$ cream. At the end of one week cure rate was observed as $76 \%$ in benzyl benzoate group, $82.14 \%$ in permethrin group and $55.56 \%$ in ivermectin group. At the end of second weeks cure rate was observed as $92 \%$ in benzyl benzoate group $96.43 \%$ in permethrin group and $100 \%$ in ivermectin group. ${ }^{59}$ In Another study compared single application of benzyl benzoate, double application of benzyl benzoate and single dose of ivermectin $200 \mathrm{mcg} / \mathrm{kg}$. At the end of 2 weeks $54.4 \%$ of the patients were cured in single application of benzyl benzoate group, $68.8 \%$ of the patients were cured in double application of benzyl benzoate group and $24.6 \%$ of the patients were cured in ivermectin group. At the end of $4^{\text {th }}$ week $76.5 \%, 95.8 \%$ and $43.1 \%$ of the patients were cured respectively in single application of benzyl benzoate, double application benzyl benzoate and ivermectin group. ${ }^{60}$

The drug was also active in nodular scabies showing gradual improvement in a few reports. ${ }^{61,62}$ A transitory aggravation of pruritus is possible the first days after treatment and must not be considered as a treatment failure. ${ }^{56,63-65}$ A few open studies had reported efficacy of topical ivermectin. Yousseff et al., had used liquid form in a concentration of a $0.8 \%$ weight/ volume dilution for human ectoparasites (like Sarcoptes scabiei and Pediculus humanus capitis). Total 75 patients were included out of whom 50 had scabies and 25 had pediculosis. It was found that all the patients were cured clinically and parasitologically within 48 hours after a single application. As $50 \%$ of scabies patients had persistent itching, another application was given after 5 days to stop itching. ${ }^{51}$ Yerham et al., had used $1.87 \%$ ivermectin cream at weekly interval. Total 10 patients had been included in the study. They reported marked improvement in the condition of the patients within 2 or 3 days of the first treatment and clinical cure occurred after 2 or 3 days of second treatment. ${ }^{66}$ Victoria et al., had used ivermectin $1 \%$ solution. Total 29 patients had been included in the study. It has been reported that all the patients were cured with the two applications at weekly interval. $^{67}$

\section{Crusted scabies and immuno-compromised patients}

Different schemes have been used in the treatment of crusted scabies: ivermectin alone (in a single dose or repeated doses), or in conjunction with keratolytic agents, or topical scabicidal agents. ${ }^{64,68,69}$ In some cases a cure was achieved in crusted scabies that had been refractory to topical conventional scabicides. ${ }^{70}$ The concomitant use of topical scabicides and keratolytics improves the ability of the drug to penetrate the crust and hyperkeratotic scale. ${ }^{68,71}$

Huffam et al. observed a complete response in 8 out of 20 patients with Norwegian scabies treated with oral ivermectin $200 \mathrm{mg} / \mathrm{kg}$ combined with topical permethrin $5 \%$; however, recurrence or re-infestations occurred in half of them. ${ }^{71}$ In vitro studies showed that these relapses were not related to drug resistance. ${ }^{72}$

Oral ivermectin is an effective and cost comparable alternative to topical agents in the treatment of scabies infection. It may be particularly useful in the treatment of severely crusted scabies lesions in immunocompromised patients or when topical therapy has failed. Oral dosing may be more convenient in institutional outbreaks and in the treatment of mentally impaired patients. ${ }^{73}$

In HIV-infected patients for whom scabies is more difficult to treat, Meinking et al. reported therapeutic success in patients with common scabies. ${ }^{69}$ Alberici et al. treated 60 cases of common or crusted scabies in 39 HIVinfected patients, and obtained an optimal rate of success with the combination of topical scabicide with oral ivermectin. $^{74}$

\section{Institutions}

Outbreaks of scabies in institutions have traditionally been difficult to eradicate. Ivermectin has shown great promise in the treatment of such revised cases. Marty et al. eradicated scabies in a geriatric nursing home by the generalized distribution of the drug to the staff members and residents. ${ }^{63}$ Several other reports confirmed the ability of the oral formulation to eradicate scabies in different epidemic or endemic situations in nursing homes. ${ }^{14,15,16,75}$

\section{SUMMARY}

Ivermectin is used for many disorders in dermatology. Systemic ivermectin administration offers several advantages over standard therapy of scabies, pediculosis, demodicidosis, larva migrans, myiasis, filariasis, and other parasitic infestations with cutaneous tropism. Still further studies are required to precisely define the optimal therapeutic uses for ivermectin in dermatology.

\section{REFERENCES}

1. Del Guidice P, Marty P. Ivermectin: A new therapeutic weapon in dermatology? Arch Dermatol 1999;135:705-6. 
2. Dourmishev AL, Dourmishev LA, Schwartz RA. Ivermectin: pharmacology and application in dermatology. Int J Dermatol 2005;44:981-8.

3. Bennett DG. Clinical pharmacology of ivermectin. JAMA 1986;189:100-4.

4. Turner MJ, Schaeffer JM. Mode of action of ivermectin. In: Campbell WC, editor. Ivermectin and Abamectin, New York: Springer Verlag. 1989;73-88.

5. Dent JA, Davis MW, Avery L. avr-15 encodes a chloride channel subunit that mediates inhibitory glutametric neuro transmission and ivermectin sensitivity in Caenorhabditis elegans. EMBO J 1997; 16:5867-79.

6. Burkhart CN, Burkhart CG. Ivermectin: a few caveats are warranted before initiating therapy for scabies. Arch Dermatol 1999;135:1549-50.

7. Campbell WC. Ivermectin, an antiparasitic agent. Med Res Rev 1993;13:61-79.

8. Edwards G, Dingsdale A, Helsby N, et al. The relative systemic availability of ivermectin after administration as capsule, tablet, and oral solution. Eur J Clin Pharmacol 1988;35:681-4.

9. Fink DW, Porra AG. Pharmacokinetics of ivermectin in animals and humans. In: Campbell WC, editor. Ivermectin and Abamectin, New York: Springer Verlag.1989;113-30.

10. Aranzazu GC, Ana M. Sahagun P, Jose DLM et al. The Pharmacokinetics and Interactions of Ivermectin in Humans- A mini Review. AAPS J 2008;10:42-46.

11. Baraka OZ, Mahmoud BM, Marschke CK, et al. Ivermectin distribution in the plasma and tissues of patients infected with Onchocerca volvulus. Eur J Clin Pharmacol 1996;50:407-10.

12. Haas N, Lindemann U, Frank K, et al. Rapid and preferential sebum secretion of ivermectin: a new factor that may determine drug responsiveness in patients with scabies. Arch Dermatol 2002;138:1618-9.

13. Whithworth JA, Morgan D, Maude GH, Downham MD, Taylor DW. A community trial of ivermectin for onchocerciasis in Sierra Leone: clinical and parasitological responses to the initial dose. Trans R Soc Trop Med Hyg 1991;85:92-6.

14. Paasch U, Haistein UF. Management of endemic outbreaks of scabies with allethrin, permetrin and ivermectin. Int J Dermatol 2000;39:463-70.

15. Barkwell R, Shiels S. Deaths associated with ivermectin treatment of scabies. Lancet 1997;349:1144-5.

16. Reintjes R, Hoek C. Deaths associated with ivermectin for scabies. Lancet 1997;350:215.

17. Alexander NDE, Bockaric MJ, Kastens WA. Absence of ivermectin associated excess deaths [letter]. Tran R Soc Trop Med Hyg 1998;92:342.

18. Hoerauf A, Mand S, Adjei O, Fleischer B, Buttner DW. Depletion of wolbachia endobacteria in Onchocerca volvulus by doxycycline and microfilaridermia after ivermectin treatment. Lancet 2001;357:1415-6.

19. Awadzi K, Opoku NO, Attah SK, et al. The safety and efficacy of amorcazine in African onchocerciasis and the influence of ivermectin on the clinical and parasitological response to treatment. Ann Trop Med Parasitol 1997;91:281-96.

20. Awadzi K, Edwards G, Opoku NO, et al. The safety, tolerability and pharmacokinetics of levamisole alone, levamisole plus ivermectin, and levamisole plus albendazole and their efficacy against Onchocerca volvulus. Ann Trop Med Parasitol 2004;98:595-614.

21. Ismail MM, Jayakody RL. Efficacy of albendazole and its combinations with ivermectin or diethylcarbamazine (DEC) in the treatment of Trichuris trichiura infections in Sri Lanka. Ann Trop Med Parasitol 1999;93:501-4.

22. Shu EN, Onwujekwe EO, and Okonkwo PO. Do alcoholic beverages enhance availability of ivermectin? Eur J Clin Pharmacol 2000;56:437-8.

23. Vanapalli SR, Chen Y, Ellingrod VL, et al. Orange juice decreases the oral bioavailability of ivermectin in healthy volunteers. Annual Meeting of the American Society for Clinical Pharmacology and Therapeutics. Washington (USA). 2003 Apr 2-5.

24. Okulicz JF, Stibich AS, Schwartz RA, et al. African river blindness: onchocercoma. Intern $\mathrm{J}$ Dermatol 2004;43:170-2.

25. Aziz MA, Diallo S, Diop IM et al. Efficacy and tolerance of ivermectin in onchocerciasis. Lancet 1982;2:171-3.

26. De Sol G, Dadzie KY, Giese J, et al. Lack of adverse reactions in ivermectin treatment for onchocerciasis. Lancet 1990;335:1106-7.

27. Newland HS, White AT, Greene BM, et al. Effect of single dose ivermectin therapy on human Onchocerca volvulus infection with onchocercal ocular involvement. Br J Ophthalmol 1988;72:5619.

28. Unnasch TR. River blindness. Lancet 2002;360:182-3.

29. Gardon J, Boussinesq M, Kamgno J, GardonWendel N, Demanga-Ngangue J, Duke BO. Effects of standard and high doses of ivermectin on adult worms of Onchocerca volvulus: a randomised controlled trial. Lancet 2002;360:203-10.

30. Ottesen EA, Vijayesekaran V, Kumaraswami V, et al. A controlled trial of ivermectin and diethylcarbazamine in lymphatic filariasis. $\mathrm{N}$ Engl $\mathrm{J}$ Med 1990;322:1113-7.

31. Bockarie MJ, Alexander ND, Hyun $P$, et al. Randomized community based of annual single dose diethylcarbazamine with or without ivermectin against Wucheria bancrofti infection in human beings and mosquitoes. Lancet 1998;351:162-8.

32. Dunyo SK, Nkrumah FK, Simonsen PE. Singledose treatment of Wuchereria bancrofti infections with ivermectin and albendazole alone or in combination: evaluation of the potential for control 
at 12 months after treatment. Trans R Soc Trop Med Hyg 2000;94:437-43.

33. Caumes E, Darty A, Paris L, et al. Efficacy of ivermectin in the therapy of cutaneous larva migrans. Arch Dermatol 1992;128:994-5.

34. Caumes E, Carrieri J, Darty A, et al. A randomized trial of ivermectin versus albendazole for the treatment of cutaneous larva migrans. Am J Trop Med Hyg 1993;49:641-4.

35. Bouchard O, Houze S, Scheimann R, et al. Cutaneous larva migrans in travelers: a prospective study, with assessment of therapy with ivermectin. Clin Infect Dis 2000;31:493-8.

36. Tarlow MM, Schwartz RA. Strongyloidiasis. eMedicine Dermatology 2002. [Journal serial online]. Available at: http://author.emedicine.com /derm /topic838.htm.

37. Caumes E, Datry A, Mayorga R et al. Efficacy of ivermectin in the therapy of cutaneous larva currens. Arch Dermatol 1994;130:932.

38. Victoria Y, Trujillo R, Barreto M. Myiasis: a successful treatment with topical ivermectin. Int J Dermatol 1999;38:142-4.

39. Jelinek T, Nothdurf HD, Reider N, et al. Cutaneous myasis, review of 13 cases in travelers returning from tropical countries. Int J Dermatol 1995;34:6246.

40. Kombila M, Duong TH, Ferrer A, Perret JC, Marion MC, Nguiri C, et al. Short and long-term action of multiple doses of ivermectin on loiasis microfilaremia. Am J trop Med Hyg 1998;58:45860.

41. Boussinesq M, Gardon J, Gardon-Wendel N, Ka mgno J, Ngoumou P, Chippaux JP. Three probable cases of Loa loa encephalopathy following ivermectin treatment for onchocerciasis. Am J Trop Med Hyg 1998;58:461-9.

42. Chappuis F, Farinelli T, Loutan L. Ivermectin treatment of a traveler who returned from Peru with cutaneous gnathostomiasis. Clin Infect Dis 2001;33:e17-9.

43. Nontasut P, Bussaratid V, Chullawichit S, Charoensook N, Visetsuk K. Comparison of ivermectin and albendazole treatment for gnathostomiasis. Southeast Asian J Trop Med Public Health 2000;31:374-7.

44. del Giudice P, Chosidow O, Caumes E. Ivermectin in dermatology. J Drugs Dermatol 2003;2:13-21.

45. Momcuoglu KY, Miller J, Rosen LJ, et al. Systemic activity of ivermectin on the human body louse (Anoplura: Pediculidae). Med Entomol 1990;27:725 .

46. Glaziou P, Nguyen LN, Moulia-Pelat JP, et al. Efficacy of ivermectin for the treatment of head lice (pediculosis capitis). Trop Med Parasitol 1994;45:253-4.

47. Victoria J, Ahumada N, Gonzaile F. Pediculosis capitis. treatmento de 100 ninos con ivermectin. Acta Terap Dermatol 1997;20:99-103.
48. Burkhart CG, Burkhart CN, Burkhart KM. An assessment of topical and oral prescription and overthe-counter treatment for head lice. J Am Acad Dermatol 1998;38:979-82.

49. Burkhart CG, Burkhart CN. Oral ivermectin therapy of phthiriasis palpebrarum. Arch Ophthalmmol 2000;118:134-35.

50. Dunne CL, Malone CJ, Whitworth JA. A field study of the effects of ivermectin on ectoparasites of man. Trans R Soc Trop Med Hyg 1991;85:550-1.

51. Youssef MY, Sadaka HA, Eissa MM, et al. Topical application of ivermectin for human ectoparasites. Am J Trop Med Hyg 1995;53:652-3.

52. Macotela-Ruiz, Pena-Gonzalez G. Treatment of scabies with oral ivermectin. Gac Med Mex 1993;129:201-5.

53. Glaziou P, Cartel JL, Alzieu P, et al. Comparison of ivermectin and benzoyl benzoate for treatment of scabies. Trop Med Parasitol 1993;4:331-2.

54. Chouela EN, Abeldano AM, Pellerano G, Forgia ML, Papale RM, and Garsd A, et al. Equivalent Therapeutic Efficacy and Safety of Ivermectin and Lindane in the Treatment of Human Scabies. Arch Dermatol 1999;135:651-5.

55. Madan V, Jaskiran K, Gupta U, Gupta DK. Oral ivermectin in scabies patients: a comparison with 1\% topical lindane lotion. J Dermatol 2001;28:4814.

56. Usha V, Gopalakrishnan Nair TV. A comparative study of oral ivermectin and topical permethrin cream in the treatment of scabies. J Am Acad Dermatol 2000;42:236-40.

57. Brooks P, Grace R. Ivermectin is better than benzyl benzoate for childhood scabies in developing countries. J Paediatr Child Health 2002;38:401-4.

58. Sule HM, Thacher TD. Comparison of ivermectin and benzyl benzoate lotion for scabies in nigerian patients. Am J Trop Med Hyg 2007;76:393-5.

59. Bachewar NP, Thawani VR, Mali SN, Gharpure KJ, Shingada VP, Dakhale GN. Comparison of safety, efficacy, and cost effectiveness of benzyl benzoate, permethrin, and ivermectin in patients of scabies. Indian J Pharmacol 2009;41:9-14.

60. Fatimata LY, Eric C, Cheick AT, Bassirou N, Antoine M. Ivermectin versus benzyl benzoate applied once or twice to treat human scabies in Dakar, Senegal: a randomized controlled trial. Bull World Health Organ 2009;87:424-30.

61. Offidiani A, Cellini A, Simonetti O, Fumelli C. Treatment of scabies with ivermectin. Eur J Dermatol 1999;9:100-1.

62. Bauer J, Blum A, Sonnichsen K, Metzler G, Rassner G, Garbe C. Nodular scabies detected by computed dermatoscopy. Dermatology 2001;203:190-1.

63. Marty P, Gari-Toussaint M, Le Fichoux Y, Gaxotte P. Efficacy of ivermectin in the treatment of an epidemic of sarcoptic scabies. Ann Trop Med Parasitol 1994;88:453.

64. Del Giudice P, Carles M, Couppie P, Bernard E, Lacour JP, Marty P, Pradinaud R, Ortonne JP, 
Dellamonica P, Le Fichoux Y. Successful treatment of crusted (Norwegian) scabies with ivermectin in two patients with human immunodeficiency virus infection. Br J Dermatol 1996;135:494-5.

65. Patel A, Hogan P, Walder B. Crusted scabies in two immuno-compromised children: successful treatment with oral ivermectin. Aust J Dermatol 1999;40:37-40.

66. Yeruham I, Hadani A. Control of human scabies by topical application of ivermectin. Ann Trop Med Parasitol 1998;92:627-9.

67. Victoria J, Trujillo R. Topical ivermectin: a new successful treatment for scabies. Pediatr Dermatol 2001; 18:63-65.

68. Aubin F, Humbert P. Ivermectin for crusted (Norwegian) scabies. N Engl J Med 1995;332:612.

69. Meinking TL, Taplin D, Jorge L, et al. The treatment of scabies with ivermectin. N Engl Med J 1995;333:26-30.
70. Jaramillo-Ayerbe F, Berrio-Munoz J. Ivermectin for crusted Norwegian scabies induced by use of topical steroids. Arch Dermatol 1998;134:143-5.

71. Huffam SE, Currie BJ. Ivermectin for Sarcoptes scabiei hyperinfestation. Int $\mathrm{J}$ Infect Dis 1998;2:152-4.

72. Walton SF, Myerscough MR, Currie BJ. Studies in vitro on the relative efficacy of current acaricides for Sarcoptes scabiei var hominis. Trans R Soc Trop Med Hyg 2000;94:92-6.

73. Fawcett RS. Ivermectin use in Scabies. Am Fam Physician 2003;68:1089-92.

74. Alberici F, Pagani L, Ratti G, Viale P. Ivermectin alone or in combination with benzyl benzoate in the treatment of human immunodeficiency virusassociated scabies. Br J Dermatol 2000;142:969-72.

75. Coralith G, David I, Angelica T, Marco C, Eduardo G. Use of ivermectin to treat an institutional outbreak of scabies in low resource setting. Infect Control Hosp Epidemiol 2007;28:1337-8.

doi: 10.5455/2319-2003.ijbcp002712

Cite this article as: Chhaiya SB, Mehta DS, Kataria

BC. Ivermectin: pharmacology and therapeutic applications. Int J Basic Clin Pharmacol 2012;1:1329. 